\title{
Uma Análise do Modelo de Explicação no Behaviorismo Radical: o Estatuto do Comportamento e a Relação de Dependência entre Eventos
}

\author{
Monalisa de Fátima Freitas Carneiro Leão \\ Universidade Federal do Mato Grosso do Sul \\ Carolina Laurenti \\ Universidade Estadual de Maringá
}

\begin{abstract}
RESUMO
O objetivo deste artigo é elucidar algumas características do modelo de explicação do comportamento proposto pelo Behaviorismo Radical. Para tanto, abordamos dois aspectos: (1) a delimitação do campo explicativo, e (2) o modelo explicativo no contexto da filosofia da ciência. Com relação ao primeiro ponto, examinamos o estatuto do comportamento na explicação behaviorista radical contrastando-o com duas explicações tradicionais do comportamento: a mentalista e a fisicalista. Diferente destas últimas explicações, o Behaviorismo Radical defende o comportamento como um objeto de estudo autônomo. No contexto da filosofia da ciência, examinamos, primeiramente, algumas concepções tradicionais de relação de dependência entre eventos, como a conexão necessária e a metáfora da cadeia. Em seguida, discutimos como o modelo de explicação behaviorista radical parece ser incompatível com tais concepções. Concluímos que o Behaviorismo Radical explica o comportamento buscando redes de interdependência probabilística entre estímulos (antecedentes e consequentes) e respostas, levando em consideração a importância da história nesse processo.
\end{abstract}

Palavras-chave: behaviorismo radical; explicação do comportamento; autonomia do comportamento; relações funcionais; explicação histórica.

\section{ABSTRACT \\ An analysis of the explicative model in Radical Behaviorism: The behavior's statute and the dependence relation between events}

The article's objective is to elucidate some characteristics of the explicative model proposed by Radical Behaviorism. As such, we have approached two aspects: (1) the explicative field's delimitation, and (2) the explicative model in the context of the philosophy of the science. In relation to first point, we have examined the behavior's statute in radical behaviorist explanation contrasting it with two traditional explanations of behavior: the mentalist and the physicalist. Differenring from these last explanations Radical Behaviorism defends behavior as an autonomous subject matter. In the context of the philosophy of science, we have examined traditional conceptions about the dependence relations among events as necessary connection and chain metaphor. Soon after, we discussed how the behaviorist explanative model seems to be incompatible with these conceptions. We have concluded that Radical Behaviorism explains the behavior looking for probabilistic interdependence networks between environmental and behavioral events taking the importance of history in this process into consideration.

Keywords: radical behaviorism; explanation of behavior; functional relations; behavior's autonomy; historical explanation.

A Psicologia é um campo da ciência que tem encontrado dificuldades para definir um objeto único e particular de estudo. Talvez seja pelo fato de existirem vários sistemas psicológicos apoiados em teorias e conceitos distintos. No entanto, podemos falar, de maneira geral, que a Psicologia é uma ciência que tem por objetivo explicar o comportamento humano. Por exemplo, autores de diferentes tradições de pensamento psicológico como Jean Piaget (citado por
Bringuier, 1978, p. 12), Kurt Koffka (1935/1975, p. 37) e Burrhus Frederic Skinner (1953/2007, p. 5) defendem que a Psicologia é a ciência do comportamento. Assim, cada sistema psicológico, apoiado em sua teoria, cria ferramentas conceituais para dar conta de tal objetivo. Verificamos, então, certa relação entre as várias ciências do comportamento humano e seus diversos modelos de explicação. 
Este texto examinará uma abordagem psicológica específica, denominada Behaviorismo Radical, que tem como principal representante B. F. Skinner (19041990). Na verdade, o Behaviorismo Radical é a filosofia de uma ciência psicológica chamada Análise do Comportamento. Nesse sentido, o Behaviorismo se pronuncia sobre o objeto, o método e os constructos teóricos dessa ciência. Considerando essas distinções, nosso objetivo geral é elucidar algumas características do modelo de explicação do comportamento proposto pelo behaviorismo skinneriano.

Não obstante, uma incursão pela temática dos modelos de explicação científicos traz à tona assuntos demasiado complexos em filosofia da ciência, como o estatuto das teorias científicas, concepção de causalidade, estrutura das explicações científicas, lógica dos enunciados científicos, e assim por diante (Nagel, 1961). Por outro lado, estender essa discussão ao exame do Behaviorismo Radical traz dificuldades suplementares, uma vez que essa filosofia da ciência apresenta nuanças que abrem o flanco para diferentes interpretações dessas questões (Abib, 2003; Chiesa, $1994 / 2006)^{1}$. Tendo isso em vista, este trabalho vem encorpar essas discussões, que ainda não chegaram a termo. Mais especificamente, este texto articulará dois aspectos que parecem ser relevantes para dar visibilidade a algumas características marcantes do modelo de explicação científico na perspectiva skinneriana.

O primeiro deles refere-se ao estatuto do comportamento em uma explicação behaviorista radical. Para desenvolver esse ponto, apresentaremos algumas explicações tradicionais do comportamento humano e as principais críticas de Skinner (1953/2007, 1974/2006, 1989/1995, 1990) a essas teorias. Já nesse momento, poderemos perceber algumas diferenças desses modelos de explicação com o sistema explicativo do Behaviorismo Radical. O segundo aspecto consiste no exame da concepção skinneriana das relações de dependência entre eventos (1953/2007, 1981/1984). Essa discussão nos conduz diretamente ao contexto da filosofia da ciência. Discutiremos, nessa ocasião, algumas teorias tradicionais de relação de dependência entre eventos, e como o modelo de explicação skinneriano parece ser incompatível com elas.

\section{O estatuto do comportamento nas explicações mentalistas e fisicalistas}

Como já sugerimos no início deste texto, não é exclusividade da proposta psicológica skinneriana adotar o comportamento humano como objeto de estudo. Porém, se entendermos, de maneira geral, o compor- tamento como uma relação entre o indivíduo e o ambiente (Skinner, 1969/1980; Todorov, 2007), uma das diferenças entre as teorias do comportamento parece estar no modo de explicar essa relação. No contexto dessa discussão, o que está em jogo, agora, é o estatuto do comportamento atribuído por diferentes filosofias do comportamento: o mentalismo, o fisicalismo e o Behaviorismo Radical. Defenderemos, aqui, que a filosofia do Behaviorismo Radical é a única, dentre as demais, que parece defender o comportamento como um objeto de estudo autônomo. Vejamos, com mais detalhe, como isso se dá.

\section{Explicação mentalista}

Mentalismo é uma doutrina filosófica que atribui como "causa" do comportamento, fenômenos mentais que são de natureza especial, diferente do comportamento (Baum, 1994/2006). Aqui, a mente tem um estatuto explicativo primordial: a mente explica o comportamento e não o inverso. Assim, podemos classificar como explicações mentalistas todas aquelas que consideram o comportamento um subproduto de "causas" mentais, como sentimentos, intenção, vontade, expectativa, propósito, personalidade, eu iniciador, e assim por diante (Chiesa, 1994/2006; Skinner, 1953/ 2007).

Skinner (1974/2006) critica o mentalismo pelo menos por dois motivos: (1) por negligenciar os eventos pertencentes à história do indivíduo, que poderiam explicar o comportamento, e (2) por tais explicações paralisarem a pesquisa, tomando os fenômenos mentais como os determinantes exclusivos do comportamento, não sendo mais necessário continuar a investigação. Consideremos um exemplo para elucidar esses dois pontos. Não é incomum ficarmos satisfeitos com explicações do comportamento que geralmente invocam sentimentos ou uma personalidade como supostas "causas". Por exemplo, se perguntarmos por que João bateu em Maria talvez tenhamos como respostas: porque João tem uma personalidade agressiva; ou porque João estava com raiva. Nesse tipo de explicação, infere-se do comportamento observado de João (xingar, bater, por exemplo) uma personalidade ou um sentimento, e essa mesma inferência é usada para explicar o próprio comportamento: a pessoa se comporta agressivamente porque tem uma personalidade agressiva, e a pessoa tem uma personalidade agressiva porque se comporta agressivamente. Não se sabe o que merece um estatuto explicativo privilegiado, se é o comportamento ou a inferência a partir do próprio comportamento. 
Partindo desse exemplo, Skinner (1974/2006) sugere que indaguemos mais: por que João apresenta esse comportamento agressivo? Ou ainda, por que João está com raiva? As respostas a essas questões devem ser buscadas, segundo a perspectiva skinneriana, na história de vida e nas experiências atuais do indivíduo. Em suma, Skinner afirma que tanto o comportamento agressivo quanto o sentimento de raiva reclamam uma explicação. Mas por que os fenômenos ditos mentais, como, por exemplo, os sentimentos, são inferidos como supostas "causas" do comportamento? Uma das explicações dadas por Skinner (1974/2006) para este fato é que os sentimentos ocorrem antes ou juntos da ação: "os sentimentos ocorrem no momento exato para funcionarem como causas do comportamento" (p. 13). Todavia, quando empregamos a proximidade espaço-temporal como único critério para atribuirmos relações causais, podemos cometer a falácia post hoc, ergo propter hoc (depois disto, logo causado por isto): "se uma coisa se segue a outra, aquela foi provavelmente causada por esta" (Skinner, 1974/ 2006, p. 13). E essa é justamente a interpretação criticada por Skinner (1974/2006), sugerindo que não basta recorrer aos eventos mentais para explicar o comportamento, porque tais fenômenos também precisam ser explicados.

\section{Fenômenos mentais e Behaviorismo Radical}

Apesar de criticar a explicação mentalista do comportamento que, em última análise, o relega a um subproduto de eventos mentais, Skinner (1974/2006, 1989/1995, 1990) não parece negar a existência desses fenômenos. Essa assertiva pode soar paradoxal, pois como Skinner rejeita as explicações mentalistas, mas não os fenômenos mentais?

Dizer que Skinner (1974/2006, 1989/1995, 1990) reconhece fenômenos mentais não significa necessariamente que ele está comprometido com a filosofia mentalista. Skinner critica a interpretação mentalista dos fenômenos mentais, visto que, para ele, a mente não é uma entidade, um lugar, uma substância, um eu iniciador - uma concepção defendida pelo mentalismo. Para Skinner (1989/1995), a mente é definida em termos comportamentais: "a mente é o que o corpo faz. E o que a pessoa faz. Em outras palavras, é o comportamento" (p. 94).

Como diz o velho ditado, Skinner (1989/1995) não joga o bebê junto com a água do banho: ele dispensa o mentalismo, mas não a nomenclatura mental. Seguindo uma interpretação da mente em termos de comportamento, Skinner tenta explicar o conceito de mente analisando as várias situações ou contextos nos quais o termo "mente" é empregado: "Para entender o que significa mente, é preciso primeiro considerar percepção, idéia, sentimento, intenção e muitas outras coisas" (p. 38).

Tendo em vista essas considerações, podemos dizer que Skinner (1974/2006, 1989/1995, 1990), ao considerar fenômenos mentais, não se compromete com uma interpretação dualista, em que mente e comportamento são entidades distintas, separadas. Isso porque, para a filosofia do Behaviorismo Radical, o sentimento, como qualquer outro fenômeno mental, não tem natureza especial, diferente do comportamento. Por exemplo, o que sentimos são os estágios iniciais que ocorrem antes do nosso comportamento agir sobre o meio, ou seja, faz parte do próprio comportamento. Os fenômenos mentais são "o próprio corpo do observador, estados ou condições corporais ou, ainda, o corpo se comportando" (Gongora \& Abib, 2001, p. 12). Em última análise, podemos dizer que, na perspectiva behaviorista radical, o que existe é uma única realidade: a comportamental (Abib, 2004) - a partir da qual a mente é explicada.

\section{Explicação fisicalista e Behaviorismo Radical}

Se, no mentalismo, o que faz a mediação entre o indivíduo e o ambiente são os processos mentais de natureza especial, no fisicalismo, são os processos fisiológicos ou cerebrais. $\mathrm{O}$ cérebro, nessa teoria, vem para substituir a mente e para explicar o comportamento. Assim, o fisicalismo considera o comportamento um subproduto de processos neurofisiológicos, tomando o cérebro como "causa" do comportamento (Skinner, 1990) $)^{2}$.

Tal como no mentalismo, Skinner (1990) afirma que o cérebro não é a "causa" do comportamento, mas também requer explicação: "O cérebro é parte do corpo e o que ele faz é parte do que o corpo faz. O que o cérebro faz é parte do que precisa ser explicado" ( $p$. 1206). Em primeiro lugar, podemos dizer que a ciência skinneriana está preocupada com a explicação do comportamento do organismo como um todo, e não de partes isoladas desse organismo (Skinner, 1990). Nesse sentido, entende-se a assertiva skinneriana de que o cérebro, que faz parte do corpo, também precisa ser explicado. Em segundo lugar, a Análise do Comportamento, junto com outras ciências, como a Biologia e a Antropologia, estudam os processos que determinam "a condição daquele corpo-com-cérebro em qualquer momento" (Skinner, 1990, p. 1208), e são esses processos que explicam "por que" aquele corpo trabalha 
de uma dada maneira. Já a Fisiologia estuda o produto desses processos, e explica, então, "como" o corpo funciona, e não "por que" funciona desta ou daquela maneira (Skinner, 1990).

Não obstante, o fato de rejeitar o cérebro e os processos fisiológicos como "causas" do comportamento não significa que Skinner (1990) não reconhece o papel da Fisiologia, e suas contribuições no estudo do comportamento humano. A crítica que Skinner faz ao fisicalismo é por dar um status privilegiado à Fisiologia, isto é, aos processos neurofisiológicos que ocorrem no momento da ação para explicar a própria ação. Talvez, no futuro, com seus novos instrumentos e novos métodos, a Fisiologia será capaz de nos esclarecer mais acerca dos processos fisiológicos que ocorrem no momento em que o organismo está se comportando, isto é, como o organismo se modifica ao longo de sua história. Porém, o que ela descobrir "não pode invalidar as leis de uma ciência do comportamento, mas tornará o quadro da ação humana mais completo" (Skinner, 1974/2006, p. 183).

\section{O estatuto do comportamento na explicação behaviorista radical}

Geralmente, entende-se o fisicalismo como uma tese contraditória ao mentalismo. Porém, apesar das diferentes "causas" atribuídas ao comportamento, essas teorias parecem mais semelhantes do que podemos imaginar. Pois, tanto nas explicações mentalistas (mente substancial), como nas fisicalistas neurofisiológicas (cérebro), o comportamento é entendido como subproduto de "causas" extra-comportamentais. O comportamento perde seu caráter unitário, e passa a ser tratado como mero sintoma de processos subjacentes.

É justamente nesse ponto que se encontra uma das principais diferenças entre esses tipos de explicação e aquela proposta pelo Behaviorismo Radical. Para essa filosofia, o comportamento não é a manifestação de causas exteriores ao próprio comportamento ou à relação comportamental, sejam elas mentais ou neurofisiológicas. O comportamento é um objeto de estudo autônomo. Isso significa que Skinner (1953/2007) recorre exclusivamente às variáveis de natureza comportamental para explicar o comportamento. Talvez aí resida a radicalidade do behaviorismo skinneriano:

Não acredito que eu havia cunhado a expressão comportamentalismo radical; mas, quando me perguntaram sobre o que queria dizer com ela, eu sempre dizia: “É a filosofia de uma ciência do comportamento tratada como objeto de estudo em si mesmo, separada das explicações internas, mental ou fisiológica (Skinner 1989/1995, p. 164).
Em última análise, podemos dizer que o objeto de estudo da teoria fisicalista é a realidade física, e o objeto de estudo da teoria mentalista é a realidade mental. Já a teoria behaviorista radical "toma como objeto de estudo a realidade comportamental" (Abib, 2004, p. 58). De acordo com Skinner (1969/1980), o comportamento é a relação entre o indivíduo e o ambiente, e para explicar o comportamento é preciso explicar essa relação. Mas como devemos olhar para essa relação? Para isso, Skinner sugere uma ferramenta conceitual, denominada contingência de reforço, que irá especificar três aspectos que devem ser considerados na explicação do comportamento: "(1) a ocasião na qual ocorreu a resposta, (2) a própria resposta e (3) as consequências reforçadoras" (p. 180).

Desse modo, a noção de contingência de reforço mostra que a explicação do comportamento não requer a mediação do sistema nervoso, enfatizado pelo fisicalismo neurofisiológico, ou de processos mentais especiais, proposto pelo mentalismo, para explicar a relação do indivíduo com o ambiente. $\mathrm{O}$ que explica essa relação são as contingências de reforço. Dito de outro modo, o que explica o comportamento é o contexto no qual ele ocorre (Chiesa, 1994/2006).

Apesar de Skinner (1953/2007, 1969/1980, 1974/ 2006), com o conceito de contingência, mostrar a importância de uma inter-relação entre eventos, ele dá ênfase no papel das consequências passadas do comportamento. O ambiente não é simplesmente o lugar onde as pessoas se comportam, tampouco é algo que incita ou força o comportamento. O ambiente participa das relações comportamentais selecionando as respostas. A consequência passada seleciona a resposta, aumentando ou diminuindo a sua probabilidade de ocorrência. Assim, podemos mudar o responder modificando as consequências que se seguem a ele. Considerando a importância das consequências em seu sistema explicativo, Skinner (1953/2007, 1969/1980) sugere o termo 'operante' para definir a classe de respostas que age sobre o ambiente. Segundo o autor, "o termo dá ênfase ao fato de que o comportamento opera sobre o ambiente para gerar consequências" (Skinner, 1953/2007, p. 71). Embora Skinner enfatize o papel das consequências na seleção de respostas operantes, os eventos antecedentes também participam da relação comportamental, como veremos adiante.

Em suma, para a teoria do Behaviorismo Radical, o comportamento é um objeto de estudo primordial, assumindo um papel primário em vez de secundário. Nesse sentido, a explicação do comportamento está nas contingências de reforço. Em outras palavras, os 
analistas do comportamento explicam o comportamento descrevendo relações de dependência entre estímulos (antecedentes e consequentes) e respostas. Trata-se, então, de um modelo de explicação que não recorre a uma mente especial e ao cérebro para explicar as relações entre indivíduo e ambiente, mas sim às variáveis de natureza exclusivamente comportamental.

\section{Modelos de explicação científica e Behaviorismo Radical}

Até o momento, analisamos a delimitação do campo explicativo, mais especificamente, examinamos o estatuto do comportamento na explicação skinneriana em contraste com algumas explicações tradicionais do comportamento. Agora, discutiremos a concepção de relação de dependência entre eventos adotada pelo Behaviorismo Radical, à luz alguns temas capitais em filosofia da ciência.

Contudo, antes disso, vale esclarecer alguns posicionamentos com respeito ao assunto. Tradicionalmente, na filosofia da ciência, 'relação de dependência' é usualmente considerada sinônimo de 'causalidade' ou 'relação causal' (Schlick, 1931/1988, p. 04). Sob essa perspectiva, relações não causais remetem para eventos necessariamente erráticos, que acontecem aqui e acolá sem qualquer razão aparente. Com efeito, rejeitar a causalidade seria o mesmo que abjurar o empreendimento científico. Não obstante, a relação de identidade entre essas noções têm sido questionada (Bunge, 1959/1963; Laurenti; 2006; Mach, 1893/1960, 1905/1976): relação de dependência não se reduz à causalidade. Esta última pode ser entendida como um tipo de relação de dependência entre eventos, e não como a relação de dependência por excelência. Bunge (1959/1963), por exemplo, destaca que a causalidade remete para relações biunívocas, externas, unilaterais e inexoráveis entre eventos, ao passo que a ciência pode envolver outras relações de dependência que não se ajustam a esses critérios, como relações funcionais, teleológicas, dialéticas, estatísticas, dentre outras (Bunge, 1959/1963, pp. 17-19). Nessa linha de raciocínio, a expressão 'relação não causal' não se identifica necessariamente com 'relação casual', mas pode simplesmente assinalar outros tipos de relações de dependência, que não se ajustam aos cânones do pensamento causal.

Sem que haja espaço para nos determos mais nessa questão, adotar o conceito de relação de dependência desvinculado da causalidade parece ser uma estratégia mais útil para aquilatarmos a importância e originali- dade do modelo skinneriano de explicação do comportamento, que descreve relações de dependência entre estímulos (antecedentes e consequentes) e respostas. No contexto dessa discussão, já é possível adiantar que a "lógica" da causalidade parece ser insuficiente para explicar as complexas relações de dependência que caracterizam o comportamento.

Apresentaremos, inicialmente, duas concepções tradicionais de relação de dependência entre eventos, denominadas: conexão necessária e metáfora da cadeia. Essas duas concepções se ajustam aos cânones do pensamento causal e, portanto, podem ser identificadas como relações causais (Bunge, 1959/1963; Chiesa, 1994/2006; Hume, 1748/1980). Posteriormente, mostraremos como o modelo behaviorista radical parece se afastar de cada uma delas.

\section{Relação entre eventos como conexão necessária}

Chiesa (1994/2006) chama a atenção para o fato de que os conceitos empregados em uma explicação científica não são neutros. Subjacentes a esses conceitos existem sistemas teóricos que os definem e lhes dão sentido. Segundo a autora, é essa base de conhecimentos, a rede conceitual, que dá significado aos vários tipos de explicações. Desse modo, encontramos na ciência várias explicações das relações de dependência entre eventos, a depender da rede conceitual envolvida, às quais vem sofrendo mudanças no decorrer da história e filosofia da ciência.

No século XVII, com influência de Newton (citado por Chiesa, 1994/2006), predominava a noção de causalidade como conexão necessária. Essa concepção pressupõe que: 1) a causa tem uma conotação de força ou agência, e 2) a causa é, pelo menos, uma condição suficiente para o efeito. Na filosofia da ciência, a noção de força causal sugere que há um poder na causa que a une infalivelmente ao efeito: a causa gera ou produz o efeito. Além da noção de força, vale destacar também, que a noção de conexão necessária parece encerrar uma relação infalível ou inexorável entre causa e efeito (Chiesa, 1994/2006, p. 106; Hume, 1739/2000, p. 119). Essa infalibilidade da relação pode ser esclarecida por meio da noção de suficiência causal (Laurenti, 2006). Dizer que A é suficiente para $B$ é o mesmo que afirmar que A necessita B; ou que A garante $\mathrm{B}$. Se considerarmos A como causa e B como efeito, dizemos que, sob a ótica da noção de suficiência, a causa necessita ou obriga o efeito. Desse modo, dada a ocorrência da causa suficiente, o efeito não poderia ter sido outro. Tendo em vista a noção de suficiência causal, podemos entender a 'conexão ne- 
cessária' como uma concepção de causalidade que afirma o seguinte: todo evento A está conectado de tal modo com o evento B que, dado A, B deve ocorrer.

Em suma, a ideia de causa como força, mais a suficiência causal, definem a relação infalível e inexorável entre os eventos, típica da concepção de causalidade como conexão necessária.

\section{Críticas à concepção de conexão necessária entre eventos}

Posteriormente, no século XVIII, David Hume (1748/1980) critica a noção de causalidade como conexão necessária e propõe uma concepção de relação entre eventos em termos de relações constantes. Segundo esse autor, a experiência só nos mostra que um evento segue constantemente o outro, mas não nos permite identificar uma conexão necessária entre eles, ou seja, não podemos justificar empiricamente o elo que liga a causa ao efeito. Dando a palavra ao autor: "só aprendemos pela experiência a conjunção frequente dos objetos, sem jamais podermos perceber qualquer coisa que se pareça com uma conexão entre eles" (p. 163).

Com efeito, Hume (1748/1980) mostra que é só por meio da experiência de um evento sendo regularmente seguido por outro evento que podemos fazer atribuições causais, isto é, afirmar que o primeiro é causa do segundo. Ao entender a causalidade como uma sucessão invariável entre eventos, a causa deixa de ser uma força que produz o efeito, e passa ser interpretada como o evento que é seguido regularmente por outro evento, ou seja, um antecedente constante.

Já no século XIX, o físico Ernst Mach (1893/1960, 1905/1976), influenciado por Hume, propõe a ideia de relações funcionais como alternativa à noção de relações causais (Chiesa, 1994/2006; Laurenti, 2004). Na esteira de Hume (1748/1980), Mach (1893/1960) reconhece que o conceito de causa carrega a noção de força, que não pode ser justificada empiricamente. Além disso, Mach (1886/1959) considera o conceito de causalidade demasiado "rígido": "a concepção tradicional de causalidade é algo perfeitamente rígido: uma dose do efeito segue a uma dose da causa. Uma espécie de concepção primitiva e farmacêutica do universo é expressa nessa visão, como na doutrina dos quatro elementos" (p. 89). Com essa crítica, Mach (1886/1959) parece ter no horizonte a ideia de suficiência causal, que caracteriza uma relação inflexível entre eventos.

Tendo em vista as limitações das noções de força e suficiência causal, Mach (1886/1959) substitui o con- ceito de causa pelo de função. Nesse sentido, "A concepção moderna de causalidade substitui a noção de força pela de relações funcionais e as equações científicas se referem aos acontecimentos como função de outros acontecimentos, substituindo a noção de um evento A exercendo uma força sobre B" (Chiesa, 1994/2006, p. 107). Agora, dizemos, na perspectiva das relações funcionais, que B é função de A (Chiesa, 1994/2006). O conceito de relação funcional permite descrever uma interdependência probabilística entre eventos ou tipos de eventos. Assim, afastando-se da ideia de relações infalíveis e inexoráveis, as relações funcionais admitem que, mediante a apresentação do evento A, o evento B pode não ocorrer. Em outras palavras, a noção de dependência funcional admite exceções: a ocorrência do evento A pode ser seguida da ocorrência do evento B. Não se trata mais de uma relação de suficiência causal, mas de probabilidade de ocorrência.

É importante esclarecer que o conceito de causalidade como conexão necessária pressupõe a noção de força e sugere uma relação de suficiência causal entre causa e efeito. Considerando que as relações funcionais descrevem relações empíricas em termos probabilísticos, podemos dizer que esse modo de explicar a relação de dependência entre eventos parece ser incompatível com a noção de causalidade, especialmente, com a noção de conexão necessária entre eventos.

Em suma, à semelhança de Hume, Mach (1893/ 1960, 1905/1976) afasta-se da ideia de relação de dependência como conexão necessária, mas diferente daquele, parece substituir a noção de causalidade pelo conceito de relação funcional. A relação entre eventos passa, então, a ser explicada como dependência mútua entre eventos, que é descrita em termos de probabilidade.

\section{Explicação da relação entre eventos no Behaviorismo Radical}

Finalmente, no século XX, surge a filosofia do Behaviorismo Radical que adota as relações funcionais machianas para descrever relações de dependência entre estímulos (antecedentes e consequentes) e respostas. Skinner (1953/2007, 1969/1980), assim como Mach (1893/1960, 1905/1976) e Hume (1748/ 1980), também rejeita a noção de causa como força ou agência, bem como a ideia de uma conexão necessária entre eventos.

Desvinculando-se desses conceitos, Skinner (1953/ 2007) propõe os termos 'variável independente' (VI) e 
'dependente' (VD), como alternativa a 'causa' e 'efeito', respectivamente. Substitui também a 'conexão causal' pela 'relação funcional' sugerindo, com isso, que a relação entre o indivíduo e ambiente é uma relação de interdependência probabilística. Seguindo essa linha de raciocínio, deveríamos tratar as relações entre variável independente (VI) e variável dependente (VD) como regularidades prováveis, e não como conexões infalíveis. Com base na explicação skinneriana das relações de dependência entre eventos, podemos sugerir que esse modelo é incompatível com a noção de conexão necessária. O Behaviorismo Radical não pressupõe uma relação causal, e nem se compromete com as noções de suficiência e força que caracteriza uma relação inexorável entre eventos. Para esse modelo de explicação, a relação entre variáveis independentes e dependentes é funcional, ou seja, é de interdependência probabilística.

\section{Relações funcionais e contingências de reforço}

A filosofia do Behaviorismo Radical, como mencionado anteriormente, explica a relação entre indivíduo e ambiente por meio de uma ferramenta conceitual denominada contingência de reforço. Esse conceito especifica a relação entre as variáveis das quais o comportamento é função e, a partir de sua compreensão, ficam evidentes as qualidades de probabilidade e de interdependência funcional que caracterizam essa relação.

Como vimos, o comportamento operante é uma classe de respostas que produz algum efeito no ambiente gerando consequências reforçadoras (Skinner, 1953/2007, 1969/1980). Essas consequências alteram a probabilidade de emissão de futuras respostas, tornando a ocorrência de uma resposta da mesma classe mais provável. Nesse sentido, podemos dizer, conforme a noção de contingências de reforço, que a consequência reforçadora está em relação probabilística com a resposta. Isso parece estar de acordo com Skinner (1969/1980) quando diz que "construímos um operante ao tornarmos um reforço contingente a uma resposta, mas o fato importante, quanto à unidade resultante, não é a sua topografia, mas a sua probabilidade de ocorrência" (p. 180).

Com os conceitos de relação funcional e contingência de reforço, os estímulos antecedentes também exercem uma função, embora não seja a de eliciação (Skinner, 1969/1980). Qualquer estímulo presente, quando um comportamento operante é reforçado, pode adquirir propriedade discriminativa, no sentido de sinalizar a situação na qual uma resposta, se for emitida, terá maior probabilidade de ser reforçada. Skinner (1969/1980) esclarece o ponto: "Tal estímulo não age como aguilhão; não elicia a resposta, no sentido de forçá-la a ocorrer. É simplesmente um aspecto essencial da ocasião em que uma resposta, se for emitida, será reforçada" (p. 180). Nesse sentido, podemos dizer que a relação entre o estímulo antecedente e a resposta também é de interdependência probabilística, pois o estímulo não fixa de maneira inequívoca a ocorrência da resposta, mas simplesmente altera sua probabilidade de ocorrência.

Desse modo, podemos dizer que a resposta está em relação funcional com o estímulo discriminativo e com a consequência reforçadora. Essa relação é de interdependência, visto que a probabilidade do responder (variável dependente) está sob influência do estímulo discriminativo (variável independente) e da consequência reforçadora (variável independente). Essa relação também é probabilística, uma vez que as variáveis independentes alteram a probabilidade de ocorrência da resposta (variável dependente).

\section{Relação entre eventos como cadeia causal: a metáfora da cadeia}

Além da noção de conexão necessária, outra concepção tradicional de relação de dependência entre eventos, muito utilizada na ciência, está ligada à noção de cadeia causal (Chiesa, 1994/2006). Essa concepção denominada metáfora da cadeia, não envolve necessariamente a noção de força, mas pode ser caracterizada por dois aspectos principais, típicos do pensamento causal, a saber, a linearidade e a contiguidade.

O primeiro aspecto pressupõe que os eventos estão numa relação de sucessão, semelhante a uma cadeia, ou seja, uma sequência de elos ligados um ao outro, na qual há início, meio e fim identificáveis. Esse modelo sugere que especifiquemos conexões causais ponto-a-ponto: o evento A causa o evento B que, por sua vez, causa o evento $C$, e assim sucessivamente (Chiesa, 1994/2006). O segundo aspecto sugere que os eventos, numa relação causal, devem estar próximos no espaço e no tempo. Assim, a causa é necessariamente contígua ao seu efeito. Segundo essa concepção, as lacunas entre causa e efeito devem ser preenchidas por uma sequência sucessiva de eventos, permitindo, então, uma explicação causal da relação entre os acontecimentos (Chiesa, 1994/2006).

O modelo explicativo behaviorista radical parece ser incompatível com a noção de cadeia causal. De um 
lado, o behaviorismo skinneriano explica o comportamento recorrendo a uma inter-relação complexa entre variáveis, desvinculando-se da ideia de linearidade da relação entre os eventos. Por outro lado, Skinner (1981/1984) adota o modelo de seleção pelas consequências que, ao enfatizar as consequências passadas do comportamento, opõe-se à noção de contiguidade, característica da metáfora da cadeia.

\section{Linearidade versus complexidade}

Para o modelo de explicação skinneriano, a relação entre os eventos não parece ser linear, mas sim, uma rede de inter-relações funcionais entre variáveis independentes e dependentes. Para elucidar essa ideia, Skinner (1953/2007, 1957/1978) mostra como as variáveis independentes e dependentes podem se relacionar de maneira complexa. Em um caso, "(1) a força de uma única resposta pode ser, e usualmente é, função de mais de uma variável" (Skinner, 1957/1978, p. 273), em outras palavras, isso significa que muitas variáveis independentes podem influenciar a probabilidade de ocorrência de uma única resposta (variável dependente). Ademais, “(2) uma única variável costuma afetar mais de uma resposta" (p. 273). Aqui, Skinner mostra que uma variável independente pode estar em relação funcional com diversas variáveis dependentes.

Tendo em vista essa complexidade, o comportamento parece demandar explicações na forma de teias de relações entre variáveis, e não como uma linha reta, característica da metáfora da cadeia. Nesse sentido, a noção de linearidade da metáfora da cadeia parece ser insuficiente para explicar a multiplicidade de relações entre eventos, típica das relações comportamentais.

\section{Contiguidade versus seleção pelas consequências}

Como mencionado anteriormente, o modelo explicativo skinneriano dá ênfase à função seletiva das consequências passadas do comportamento. Skinner (1981/1984) adota a seleção pelas consequências como modelo explicativo do comportamento, sugerindo que este último é produto de três níveis de variação e seleção: filogenética, ontogenética e cultural. Para os propósitos deste texto vale ressaltar o caráter histórico do modelo de seleção pelas consequências: as consequências passadas selecionam variações comportamentais ao longo do tempo. No nível filogenético são consequências de sobrevivência da espécie, no nível ontogenético são consequências reforçadoras no âmbito individual, e no nível cultural são as consequências culturais (de sobrevivência das culturas).
Nesse sentido, o modelo skinneriano de seleção pelas consequências mostra que o comportamento é produto de uma história evolutiva de seleção e variação. Considerando o segundo nível de seleção, domínio da Psicologia, o modelo de seleção pelas consequências sugere que olhemos para a história de reforçamento do comportamento do indivíduo, pois, para esse modelo explicativo, os eventos imediatos, que ocorrem no momento em que a resposta é emitida, não são suficientes para explicar o comportamento (Skinner, 1981/1984).

Levando em consideração a proposta de uma explicação histórica do comportamento, esse modelo parece ser incompatível com a ideia de contiguidade, característica da metáfora da cadeia. A seleção pelas consequências não pressupõe necessariamente uma contiguidade espaço-temporal entre eventos, pois considera também, e principalmente, a relação entre respostas e eventos ambientais ao longo do tempo (Chiesa, 1994/2006). Em suma, o modelo explicativo de seleção pelas consequências sugere uma explicação histórica e não mais episódica, pois, a função dos eventos imediatos só será explicada recorrendo à história de seleção e variação do comportamento do indivíduo. Seguindo essa linha de raciocínio, podemos dizer que as variáveis das quais o comportamento é função se encontram no seu "ambiente imediato e em sua história ambiental”" (Skinner, 1953/2007, p. 33).

\section{CONCLUSÃO}

O Behaviorismo Radical constitui uma das propostas psicológicas que tem como objetivo explicar o comportamento humano. Entretanto, seu modelo de explicação apresenta algumas características que permitem entendê-lo como um sistema peculiar.

Inicialmente, investigamos o estatuto do comportamento na explicação behaviorista radical, contrastando-o com algumas explicações tradicionais do comportamento humano. Verificamos que, apesar do fisicalismo ser comumente apresentado como uma tese contraditória ao mentalismo, essas doutrinas filosóficas, do ponto de vista do estatuto explicativo do comportamento, apresentam mais semelhanças do que diferenças. Em outras palavras, podemos dizer que são dois lados da mesma moeda, pois, ambas consideram o comportamento um mero sintoma de processos subjacentes (mentais e fisiológicos). Nesse sentido, o Behaviorismo Radical não é compatível nem com o mentalismo, nem com o fisicalismo, já que essa filosofia adota o comportamento como um objeto de estudo autônomo. 
Com o conceito de contingências de reforço, Skinner (1953/2007, 1969/1980) parece garantir o comportamento como objeto de estudo em si mesmo, na medida em que explica o comportamento recorrendo a uma inter-relação entre eventos ambientais e respostas. No contexto da filosofia da ciência, podemos dizer que a herança filosófica do conceito de contingências de reforço distancia o modelo de explicação behaviorista radical de algumas concepções tradicionais de relação de dependência entre eventos, como as noções de conexão necessária e metáfora da cadeia.

Em primeiro lugar, o Behaviorismo Radical critica a ideia de conexão necessária entre eventos. Na esteira de Hume (1748/1980), Skinner (1953/2007, 1969/1980) sugere que a experiência não mostra relações inexoráveis, mas sim regularidades prováveis. Nesse sentido, o sistema skinneriano emprega as noções de variável independente e dependente em substituição à noção de causa e efeito, respectivamente. Além disso, adota a noção de relação funcional de Ernst Mach (1893/ 1960, 1905/1976) em substituição à noção de conexão necessária, permitindo, com isso, descrever uma interdependência probabilística entre eventos.

Em segundo lugar, tal substituição realça a incompatibilidade do modelo de explicação skinneriano com a concepção da metáfora da cadeia, a qual pressupõe que os eventos estão relacionados linearmente e, para tanto, devem estar contíguos no espaço e no tempo. De um lado, o modelo de explicação behaviorista radical propõe que os eventos podem se relacionar de diferentes modos, formando uma rede de inter-relações entre variáveis independentes e dependentes. Essa complexidade contrapõe-se à ideia de cadeia linear. Por outro lado, o modelo de seleção pelas consequências, que sugere uma explicação histórica, parece ser incompatível com uma explicação que se restringe aos eventos imediatos, como defendida pela metáfora da cadeia.

O conceito de contingência de reforço parece mostrar todas essas características do modelo de explicação proposto pelo Behaviorismo Radical. A relação entre estímulo discriminativo, resposta e consequência reforçadora é de interdependência mútua, ou seja, um influencia o outro de maneira probabilística: as variáveis independentes alteram a probabilidade de ocorrência de variáveis dependentes. Além do mais, a resposta pode estar em relação funcional com uma multiplicidade de eventos. Do mesmo modo, uma variável independente pode estar em relação funcional com diversas respostas. Destaca-se, assim, uma rede de inter-relações. Por fim, o comportamento do indi- víduo pode ser entendido como o produto de uma história de seleção de variações (respostas) por eventos ambientais (consequências) diante de condições específicas (antecedentes) ao longo do tempo e, portanto, temos, aqui, uma explicação histórica do comportamento.

Em suma, após examinarmos algumas características do modelo explicativo skinneriano, podemos dizer que o Behaviorismo Radical explica o comportamento sem ferir o nível comportamental, buscando redes de interdependência probabilística entre eventos ambientais e respostas, levando em consideração a importância da história nesse processo.

\section{REFERÊNCIAS}

Abib, J. A. D. (2004). O que é comportamentalismo? Em M. Z. S. Brandão, F. C. S. Conte, F. S. Brandão, I. K. Ingberman, V. L. M. da Silva, \& S. M. Oliani (Orgs.), Sobre comportamento e cognição: Vol. 13. Contingências e metacontingências: Contextos socioverbais e o comportamento do terapeuta (pp. 52-61). Santo André, SP: ESETec.

Abib, J. A. D. (2003). Behaviorismo radical e interpretação. Em M. Z. S. Brandão, F. C. Conte, F. S. Brandão, Y. K. Ingberman, C. B. Moura, V. M. Silva \& S. M. Oliani (Orgs.), Sobre comportamento e cognição: Vol. 11. A história e os avanços, a seleção por consequências em ação (pp. 57-65). Santo André, SP: ESETec.

Baum, W. M. (2006). Compreender o behaviorismo: Ciência, comportamento e cultura ( $2^{\mathrm{a}}$ ed.). (M. T. A Silva, M. A. Matos, G. Y. Tomanari, \& E. Z. Tourinho, Trad.). Porto Alegre: Artmed. (Original publicado em 1994)

Bringuier, J. C. (1978). Conversando com Jean Piaget. São Paulo: Difel.

Bunge. M. (1963). Causality. New York: World Publishing. (Original publicado em 1959)

Chiesa, M. (2006). Behaviorismo radical: A filosofia e a ciência (C. E. Cameschi, Trad.). Brasília: Celeiro/IBAC. (Original publicado em 1994)

Gongora, M. A. N., \& Abib, J. A. D. (2001). Questões referentes à causalidade e eventos privados no behaviorismo radical. Revista Brasileira de Terapia Comportamental e Cognitiva, 3, 9-24.

Hume, D. (2000). Do entendimento (D. Danowski, Trad.). Em Tratado da natureza humana (pp. 15-306). São Paulo: Unesp. (Original publicado em 1739)

Hume, D. (1980). Investigação sobre o entendimento humano (A. Sérgio, Trad.). Em V. Civita (Org.), Os pensadores: Berkeley/ Hume ( $2^{\mathrm{a}}$ ed.) (pp. 135-204). São Paulo: Abril Cultural. (Original publicado em 1748)

Koffka, K. (1975). Principios da psicologia da Gestalt (A. Cabral, Trad.). São Paulo: Cultrix/EDUSP. (Original publicado em 1935)

Laurenti, C. (2006). Um exame crítico do conceito de causalidade no behaviorismo radical. Em H. J. Guilhardi, \& N. C. de Aguirre (Orgs.), Sobre comportamento e cognição: Vol. 17. Expondo a variabilidade (pp. 81-88). Santo André, SP: ESETec. 
Laurenti, C., \& Lopes, C. E. (2008). Uma explicação não-causal do comportamento no behaviorismo radical. Acta Comportamentalia, 16(3), 379-397.

Lopes, C. E. (2008). Uma proposta de definição de comportamento no behaviorismo radical. Revista Brasileira de Terapia Comportamental e Cognitiva, 10, 1-13.

Mach, E. (1976). Knowledge and error: Sketches on the psychology of enquiry (T. J. MacCormack \& P. Foulkes, Trad.). Boston: Reidel. (Original publicado em 1905)

Mach, E. (1960). The science of mechanics: A critical and historical account of its development (T. J. McCormack, Trad.). Illinois: Open Court. (Original publicado em 1893)

Mach, E. (1959). The analysis of sensations (C. M. Williams, Trad.). New York: Dover Publications. (Original publicado em 1886)

Nagel, E. (1961). The structure of science: Problems in the logic of scientific explanation. New York: Hardcover, Brace \& World.

Schlick, M. (1988). A causalidade na física atual (L. J. Baraúna \& P. R. Mariconda, Trads.). Em V. Civita (Org.), Os pensadores: Schlick/Carnap (pp. 03-37). São Paulo: Nova Cultural. (Original publicado em 1931)

Skinner, B. F. (1978). O comportamento verbal (M. P. Villalobos, Trad.). São Paulo: Cultrix. (Original publicado em 1957)
Skinner, B. F. (1980). Contingências do reforço: Uma análise teórica (R. Moreno, Trad.). Em V. Civita (Org.), Os Pensadores: Pavlov/Skinner. São Paulo: Abril Cultural. (Original publicado em 1969)

Skinner, B. F. (1984). Selection by consequences. Behavioral and Brain Sciences, 7, 473-724. (Original publicado em 1981)

Skinner, B. F. (1990). Can psychology be a science of mind? American Psychologist, 45, 1206-1210.

Skinner, B. F. (1995). Questões recentes na análise comportamental (A. L. Neri, Trad.). Campinas: Papirus. (Original publicado em 1989)

Skinner, B. F. (2006). Sobre o behaviorismo (10 a ed.) (M. P. Villalobos, Trad.). São Paulo: Cultrix. (Original publicado em 1974)

Skinner, B. F. (2007). Ciência e comportamento humano (11 ${ }^{\mathrm{a}} \mathrm{ed}$.) (J. C. Todorov, \& R. Azzi, Trad). São Paulo: Martins Fontes. (Original publicado em 1953)

Todorov, J. C. (2007). A psicologia como o estudo das interações. Psicologia: Teoria e Pesquisa, 23, 57-61.

Recebido: 30/09/2008

Última revisão: 13/04/2009

Aceite final: 30/04/2009

\section{Notas:}

1 Por exemplo, no tocante ao papel das teorias científicas em uma ciência do comportamento, Chiesa (1994/2006) aproxima o behaviorismo skinneriano do descritivismo científico, ao passo que Abib (2003), além dos aspectos descritivistas, ressalta também elementos instrumentalistas. Há quem argumente que o modelo de explicação behaviorista radical apresenta uma concepção de causalidade distinta da mecânica clássica (Chiesa, 1994/2006); outros advogam que o behaviorismo skinneriano tem afinidades com uma concepção não causal de explicação científica (Laurenti \& Lopes, 2008).

2 Estamos tratando, aqui, de um tipo de fisicalismo - o neurofisiológico. Mas vale a pena mencionar que há outro tipo de fisicalismo, o ambiental, que trata o ambiente como algo externo ao comportamento. Em uma perspectiva relacional, não há ambiente fora da relação comportamental (Lopes, 2008).

\section{Sobre as autoras:}

Monalisa de Fátima Freitas Carneiro Leão: Aluna do curso de Psicologia da Universidade Federal do Mato Grosso do Sul - Campus Paranaíba.

Carolina Laurenti: Professora no curso de Psicologia da Universidade Estadual de Maringá.

Endereço para correspondência: Av. Padre Valim, 291 - Bairro Nossa Senhora de Fátima - 38280-000 Iturama, MG - Endereço eletrônico:mona_freitas@hotmail.com. 